East African Medical Journal Vol. 87 No. 4 April 2010

DELAYED PRESENTATION OF BREAST CANCER PATIENTS

E.S. Otieno, MBChB, MMed (Surg), PGDRM, Lecturer, Department of Medical Physiology, College of Health Sciences, University of Nairobi, P.O. Box 5510-00100, Nairobi, Kenya, J.N. Micheni, MBChB, MMed (Surg.), Consultant Surgeon and Director, Kenyatta National Hospital, P.O. Box 19961-00202, Nairobi, Kenya, S.K. Kimende, MBChB, MMed (Surg.) Lecturer, Department of Surgery, College of Health Sciences, University of Nairobi, P.O. Box 19176-00202, Nairobi, Kenya and K.K. Mutai, BSc, PGDRM, Epidemiologist, P.O. Box 24296-00100, Nairobi, Kenya

Request for reprints to: Dr. E.S. Otieno, Department of Medical Physiology, College of Health Sciences, University of Nairobi, P.O. Box 5510-00100, Nairobi, Kenya

\title{
DELAYED PRESENTATION OF BREAST CANCER PATIENTS
}

\author{
E.S. OTIENO, J. N. MICHENI, S.K. KIMENDE and K.K. MUTAI
}

\begin{abstract}
Objective: To determine the extent and nature of delayed presentation of patients treated for breast cancer at Kenyatta National Hospital (KNH).

Design: Prospective cross sectional study.

Setting: Kenyatta National Hospital (KNH) which is a tertiary, teaching and referral hospital in Nairobi, Kenya.

Results: A total of 166 patients were recruited into the study. The mean age was 47 years with a range between 17 and 88 years. Females constituted $98.8 \%$, had an average of 4.5 children per subject with a median of 4 and a range of 0-11. A lump as the first noticed symptom present in $87.3 \%$ and $52.1 \%$ were pre-menopausal. Only $11(6.62 \%)$ patients presented within 30 days of discovering their breast symptom, $34(20.4 \%)$ presented between thirty and ninety days and the remaining $115(73.1 \%)$ presented three months after noticing their symptom. Three reasons accounted for $67.5 \%$ of the delay. Thirty three (19.9\%) kept away fearing that they would be told they had cancer while $39(23.5 \%)$ presented late because their breast symptom was painless. Another $40(24.1 \%)$ said they had earlier visited medical personnel who had reassured them that their symptoms were benign.

Conclusion: Majority of patients treated for advanced breast disease presented to the healthcare providers at KNH more than three months after noticing their breast symptom and a sizeable number of patients were being reassured falsely that they have benign disease without the benefit of biopsy.
\end{abstract}

\section{INTRODUCTION}

Breast cancer remains a leading cause of death of women all over the world. Presentation of patients with this cancer in late stage (Manchester III and IV) is rare in the Western World (1). On the contrary, late stage presentation is common in developing countries especially so in the African sub-continent. In this region the prevalence of advanced breast cancer at presentation ranges between 57 and $95 \%$ (1-5). Patient delay defines the time lapse between noticing a breast symptom and presenting to the healthcare provider or facility. Randomised trials have established that patient delay of three or more months at presentation is associated with significantly higher levels of recurrence and lower survival rates $(6,7)$. Patient delay accounts for a large proportion of those who present with late stage disease especially in developing countries. Understanding the factors that influence patient delay is critical in order to develop effective and targeted interventional programmes to shorten this delay and hence provide women suffering from breast cancer with a better opportunity for survival.

\section{MATERIALS AND METHODS}

Study design and setting: Prospective cross sectional study over a two and a half year period from $1^{\text {st }}$ October 2003 to 31 $1^{\text {st }}$ March 2006 carried out at Kenyatta National Hospital (KNH) in the three surgical firms and the breast clinic. The KNHbreast clinic was set up in the year 2000 as a specialist clinic for the purpose of managing all diseases of the breast. It is held once a week and run by consultant surgeons and surgical residents in training.

Study population: All patients seen at the KNH breast clinic or admitted to the three surgical wards with cytologically or histologically diagnosed advanced 
breast cancer (Manchester classification 1940-Stage III and IV) were included in this study. Patients who presented with previously treated or recurrent breast cancer were excluded from the study.

Data collection: All patients diagnosed with breast cancer who certified the inclusion criteria were interviewed by the researchers and socio-clinical and demographic data entered into a structured questionnaire after written consent was obtained from the patient or guardian.

Ethical issues: Written permission to do the study was granted by the Kenyatta National Hospital Research and Ethics Committee

\section{RESULTS}

A total of 166 patients were recruited into the study. The mean age was 47 years with a range between 17 and 88 years. Females constituted $98.8 \%$. The study population had an average of four point five children per subject with a median of four and a range of $0-11$. A lump as the first noticed symptom was seen in $87.3 \%$ and $52.1 \%$ were pre-menopausal. Table 1 summarizes the duration of symptoms in three groupings. Three reasons accounted for $67.5 \%$ of the delay. Thirty three (19.9\%) kept away fearing that they would be told they had cancer while 39 (23.5\%) presented late because their breast symptom was painless. Another $40(24.1 \%)$ said they had earlier visited a medical personnel who had reassured them that their symptoms were benign. Table 2 gives more details of reasons given for the delay.

\section{DISCUSSION}

For purposes of management, breast cancer is clinically divided into early and late disease. The former constitutes patients presenting with stage I and II, while the latter consists of stage III and IV according to Manchester classification 1940. Our present day knowledge of breast cancer is such that there is no effective primary prevention, making it imperative to detect the disease early in order to increase the likelihood of cure (8). There is indeed increasing evidence that patient delay at presentation adversely affects survival $(6,7)$. Richards et al. (9) found that a delay of 12 weeks or more resulted in significantly higher levels of recurrence and worse survival rates. In the West only one third (30\%) of women presenting with symptomatic breast cancer have a patient delay of three or more months $(10,11)$. Even then, presentation of breast cancer with advanced disease is rare in the developed world owing to awareness campaigns, limited practice of breast self examination (BSE) and widespread use of mammography screening (11). On the contrary, in developing countries and especially in Africa, presentation of breast cancer with stage III and stage IV is very common (1-5). In Nigeria over the last 40 years therehas been progressiveimprovement in the stage at presentation of this disease. In the 1960 's Pearson found a late stage disease prevalence of $95 \%$. This dropped to $84 \%$ in the 1970 's, $77 \%$ in the late 1980's and 57\% in the 1990's (5). Comparatively at Muhimbili Medical Centre in Tanzania, Hiza and Aziz (3) found that up to $85 \%$ of patients with breast cancer presented with late stage disease in a study done between 1978 to 1982. In the same institution,

Table 1

Duration of symptoms

\begin{tabular}{lccc}
\hline Duration of symptoms & $\begin{array}{c}\text { Number } \\
(\mathrm{n}=166)\end{array}$ & Cumulative percentage \\
\hline$<30$ days & 11 & 6.62 & 6.62 \\
$31-90$ days & 34 & 20.40 & 27.02 \\
$>90$ days & 115 & 73.08 & 100.00 \\
\hline
\end{tabular}

Table 2

Reasons for delayed presentation of patients with stage III and IV disease

\begin{tabular}{lccc}
\hline Reason for delay & $\begin{array}{c}\text { Number } \\
(\mathrm{n}=166)\end{array}$ & $\begin{array}{c}\text { Cumulative } \\
\text { percentage }\end{array}$ \\
\hline $\begin{array}{l}\text { Reassured that their condition was benign by } \\
\text { the first medical personnel they visited }\end{array}$ & 40 & 24.1 & 24.1 \\
$\begin{array}{l}\text { Painless symptomatology } \\
\text { Worried they would be diagnosed with cancer }\end{array}$ & 39 & 23.5 & 47.6 \\
Attending to traditional healers & & 19.9 & 67.5 \\
and taking herbal preparations & 16 & 9.6 & 77.1 \\
Not aware of the disease & 13 & 7.8 & 84.9 \\
others & 25 & 15.1 & 100 \\
\hline
\end{tabular}


Mbonde et al. (2) in a study in the mid 90s found that the prevalence rate for late disease was $93 \%$. At Mulago Hospital, Uganda, $88 \%$ of all patients with breast cancer presented to hospital with advanced disease in 1988. In Kenya, while studying postsurgical management of patients with breast cancer at Kenyatta National Hospital, Othieno-Abinya et al. (1) found a late prevalence disease of $69.5 \%$ in patients seen between 1989 to 2000. This trend is repeated in most other developing countries $(12,13)$. This study does reveal that more than $69.3 \%$ of those who presented with late disease had patient delay of more than three months and that slightly over half were pre-menopausal with a mean age of 47 years. Efforts all over the world to catch breast cancer early have revolved around creating awareness in women, the use of BSE and mammographic screening. Randomised trials of mammographic screening have provided strong evidence that early diagnosis and treatment of breast cancer can reduce specific mortality.

Theworldwideuseandefficacyofmammography for screening purposes is still controversial. This screening modality is not practical in most developing countries on account of availability and cost. However even where it is available and in use its sensitivity in identifying breast cancer is about $80 \%$ (14). It is even less efficacious in younger women below 40 years of age owing the density of the breasts. Indeed, some studies have categorically stated that false negative mammography findings have led to complacency among physicians resulting in late presentation of breast cancer $(15,16)$. Langlands and Tivers in 1982 reported five cases of negative mammograms in patients with palpable breast tumors who later presented with locally advanced breast cancer (15) and Walker noted that failure of mammography to define cancer in 95 of 218 patients with breast cancer led to serious delay after biopsy was postponed (16). However, despite a mammographic accuracy of $83 \%$ and a false negative rate of $11 \%$, Cregan et al. (14) in his series found that this did not contribute to delay at presentation or undue postponement of biopsy. Mammography alone, however, should not be used to exclude presence of breast cancer especially in women under 35 years of age with symptomatic breast disease without recourse to biopsy. This study reports that slightly over $52 \%$ of the patients seen were pre-menopausal implying a younger population among whom mammography screening may have low sensitivity. It is also relatively out of reach or most patients on account of availability and cost.

Breast Self Examination (BSE) is an inexpensive, easy to perform and quite effective means of detecting breast lumps early. In the absence of widespread mammographic screening especially in developing countries, BSE remains the most pratical way to go. Despite high level of awareness this relatively cheap but effective tool is not being practised as often as it should as the level of skill and motivation required for effective BSE is high. Philip et al. (17) reported a prospective study of 304 patients with newly diagnosed breast cancer and established a BSE compliance rate of $54 \%$. The compliant group was noted to present with clinically early tumours. A general survey in 63 hospitals in Italy found that BSE was practiced by $34 \%(n=1110)$ and that only $9 \%$ of these, did it regularly on a monthly basis (18). In this study any type of BSE (regular or irregular) resulted in smaller primaries at presentation. However, only in the regular group was there limited benefit in terms of nodal involvement and pathologic staging. It was alsonoted that the benefit that may accrue from timely presentation following BSE may be cancelled by delays inherent in out healthcare systems $(18,19)$.

Indeed, one of the most talked about causes of delay at diagnosis continues to be physician reassurance to the patient that a breast lump is benign without the benefit of biopsy. This factor was quite prominent in this study where up to $24.1 \%$ gave this as the sole reason why they had presented with advanced breast disease. This emphasizes the importance that physicians must place on biopsy as a gold standard for the diagnosis of any lesion in the breast no mater how benign it may appear.

Age and level of education are also independent factors likely to predict late stage disease at presentation. Ikpat et al (20) in Nigeria noted that $19.4 \%$ of patients aged 40 years and below presented with late stage disease compared to $73.3 \%$ of patients aged over 40 years. Personal, economic, physical and socio-cultural factors have also been documented to be causes of delay at presentation (21).

Breast size and presentation of breast disease initially without a lump have been known to cause delay $(6,21)$. In Australia it was established that whether breast size was assessed in terms of weight or thickness (mastectomy specimen), large breasts presented consistently with larger tumours and more involvement of regional lymph nodes (21). Fear of mastectomy and its associated stigma led to late presentation in $2154(44.7 \%)$ of all patients with breast cancer in Nigeria (22).

Preference from theonset for spiritual healing and traditional doctors accounted respectively for 13.5\% and $23.1 \%$ of patient delay that resulted in presentation with advanced breast disease $(19,22-24)$.

\section{ACKNOWLEDGEMENTS}

To the Director, Kenyatta National Hospital for allowing us to access the hospital records and granting permission to publish this paper. I would also like to acknowledge the hard work done by $\mathrm{H}$. Cherono and P. Oyiro who were medical students at the time. 


\section{REFERENCES}

1. Othieno-Abinya, N. A., Nyabola. L.O., Abwao, H.O. and Ndege, P.G. Post-surgical management of patients with breast cancer at Kenyatta National Hospital. East Afr. Med. J. 2002; 79: 156-162.

2. Ssali, C.J. Chemotherapy for advanced breast cancer. The Proceedings of the Association of Surgeon of East Africa. 1984; 198-200.

3. Hiza, R. and Aziz, R. Breast Cancer in Tanzania. The Proceedings of the Association of Surgery of East African. 1985: 123-125.

4. Mbonde, M.P., Amir, H., Akslen, A. and Kitinya, J.N Expression of estrogen and progesterone receptors, Ki67, p53, and Bcl - 2 Proteins, Cathepsin D. Urokinase plasminogen activator and urokinase plasminogen activator receptors in Carcinoma of the female breast in an African population. East Afr. Med. J. 2001; 78: 360 - 369.

5. Anyanwa, S.N.C. Survival following treatment of primary breast cancer in Eastern Nigeria. East Afr. Med. J. 2000; 77: 539-453.

6. Burgesscc, Ramirez A.J., Richards, M.A. and Love, S.B. Who and what influences delayed presentation in breast cancer? Br. J. Cancer. 1998; 77: 1343-1348.

7. Ramirez, A.J., Westcombe, A.M., Burgers, C.C., et al. Factors predicting delayed presentation of symptomatic breast cancer: a systematic review. Lancet. 1999; 353: 1127-1131.

8. Cobert, K. Why opt for an unnecessary delay? Delays in presentation of breast cancer. Prof. Nurse J. 1994; 9: 643-645.

9. Richards, M.A., Smith, P., Ramirez, A.J., et al. The influence on survival of delay in the presentation and treatment of symptomatic breast cancer. Br. J. Cancer. 1999; 79: 858 - 864.

10. Urgess, C., Hunter, M.S. and Ramirez, A.J. Aqualitative study of delay among women reporting symptoms of breast cancer. Br. J. Gen. Pract. 2001; 51: 967-971.

11. Grunfeldi, E.A., Ramirez, A.J., Hunter, M.S. and Richards, M.A. Women's knowledge and beliefs regarding breast cancer. Br. J. Cancer. 2002; 1373.
12. Roy, A.D. The practical care of breast cancer in Africa. The Proceeding of the Association of East Africa. 1984: 203-206.

13. Amir,H., Kitinya J.N. and Parkin, D.M. Acomparative study of carcinoma of the breast in an African population. East Afr. Med. J. 1994; 71: 215-218.

14. Cregan, P.C., Parer, J.G. and Power, A.R. Accuracy of mammography in an Australian community setting. Med. J. Aust. 1998; 49: 408-410.

15. Langlands, A.O. and Tiver, K.W. Significance of a negative mammogram in patients with a palpable breast tumor. Med. J. Aust. 1982; 1: 30-31.

16. Walker, J. and Langhands, A.O. The misuse of mammography in the managerial of breast cancer. Med. J. Aust. 1986; 145: 185-187.

17. Philip, J., Harris, W.G., Haherty, C. and Joslin, C.A. Clinical measures to assess the practice and efficiency of breast self examination. Cancer. 1986; 58: 973 - 977.

18. Unknown authors: Reducing diagnostic delay in breast cancer. Possible therapeuticimplication. Cancer. 1986; 58: 1756-1761.

19. Alcoesy, and Gilbey, V. J. From attending a class on breast self examination (BSE) to coping with breast cancer; the experience of eight women. Patient Edu. Couns. 1996; 28: 133-148.

20. Ikpat, F.R., Ndoma-Egba, R. and Collan, Y. Influence of age and prognosis of breast cancer in Nigeria. East Afr. Med. J. 2002; 79: 651-657.

21. Ingram, D.M., Huang, H.Y., Catchpole, B.N. and Roberts, A. Dobig breasts disadvantage women with breast cancer? Aust. N.Z. Surg. 1989; 59: 115- 117.

22. Ajekigbe,A.T. Fear of mastectomy: the most common factor responsiblle for bite presentation of carcinoma of the breast in Nigeria. Clin. Oncol. (R. Coll. Radiol.). 1991; 3: 78-80.

23. Mitchell, J., Lannin, D.R., Mathews, H.F. and Swanson, M.S. Religion beliefs and breast cancer screening. J. Womens Health. 2002; 11: 907-915.

24. Montella, M., Crispo, A., D'Ainto, G. et al. Determinants factors for the diagnostic delay in operable breast cancer patients. Eur. J. Cancer Prev. 2001; 10: 53-59. 